\title{
Synthesis, structural characterization and thermal studies of a novel reagent 1-[(5-benzyl-1,3-thiazol-2-yl) diazenyl]naphthalene-2-ol
}

\author{
Andrii Tupys $^{1} \cdot$ Jan Kalembkiewicz $^{2} \cdot$ Yurii Ostapiuk $^{1} \cdot$ Vasyl Matiichuk $^{1} \cdot$ \\ Oleksandr Tymoshuk ${ }^{1} \cdot$ Elżbieta Woźnicka $^{2} \cdot$ Lukasz Byczyński ${ }^{2}$
}

Received: 28 April 2016/ Accepted: 14 August 2016/Published online: 30 August 2016

(c) The Author(s) 2016. This article is published with open access at Springerlink.com

\begin{abstract}
A new thiazolylazo reagent 1-[(5-benzyl-1,3thiazol-2-yl)diazenyl]naphthalene-2-ol has been synthesized via arylation of acrolein and further diazotization and diazocoupling with 2-naphthol. The chemical structure of the compound was confirmed by IR, NMR: ${ }^{1} \mathrm{H},{ }^{13} \mathrm{C}$, COSY, HSQC and SALDI-MS spectral data. The DSC method was employed to determine the melting point and the enthalpy of fusion $\left(T_{\text {fus }}=159.7{ }^{\circ} \mathrm{C}\right.$ and $\Delta H_{\text {fus }}=$ $28.0 \mathrm{~kJ} \mathrm{~mol}^{-1}$, respectively). Thermal stability and decomposition studies of the obtained azo dye were performed in air and nitrogen atmosphere using the TG technique. The evolved gases from the heated sample were registered on FTIR spectra. The decomposition of the azo dye in air atmosphere occurred in five consecutive stages. The $p K_{\mathrm{a}}$ ionization constants of the substance were determined in ethanol-water mixture $(1: 1 \mathrm{v} / \mathrm{v})$ by means of the spectroscopic method and were found to be equal to 0.41 for $p K_{\mathrm{a} 1}$ and 9.59 for $p K_{\mathrm{a} 2}$. Using the spectrophotometric procedures, the methods for determination of trace amounts of toxic metallic ions with the new reagent were characterized and limits of detection were calculated.
\end{abstract}

Keywords Dyes - Thiazolylazonaphthol - Structure elucidation - Thermal analysis - Tautomerism - Transition metals compounds

Jan Kalembkiewicz

kalembic@prz.edu.pl

1 Faculty of Chemistry, Ivan Franko National University of Lviv, Kyryla \& Mefodiya Str., 6, Lviv 79-005, Ukraine

2 Faculty of Chemistry, Ignacy Łukasiewicz Rzeszów University of Technology, Powstańców Warszawy Av., 6 , 35-959 Rzeszow, Poland

\section{Introduction}

The applications of heterocyclic azo compounds have been studied extensively during the past 50 years [1-34]. A large number of azo dyes that are prepared from diazotization of 2-aminothiazole and its derivatives and subsequent coupling of the corresponding product with phenolic or other aromatic substances have been prepared and investigated for various purposes [2]. They are found in a variety of industrial applications mainly because of their low price and color fastness [3]. Nowadays, thiazolylazo dyes are useful in the manufacture of data storage devices such as CD, DVD and Blue-ray discs [4-6]. In addition, these compounds are used for coloring numerous consumer goods, such as clothes, leather, plastics, food, cosmetics and toys [7] offering a wide spectrum of colors mainly because of the presence of chromophoric azo groups $(-\mathrm{N}=\mathrm{N}-)$.

The main applications of thiazolylazo dyes in chemistry include spectrophotometry, liquid and cloud point extraction, solid-phase extraction, electrochemistry, liquid chromatography (precolumn derivatization HPLC) and separation procedures [8-11]. Thiazolylazo dyes have also been employed as indicators, masking agents and sorbents in combination with solid supports [12]. The use of thiazolylazo reagents in procedures involving extraction (liquid-liquid or cloud point) is based on the high solubility of these compounds in organic solvents. But unfortunately azo dyes and their chelate complexes with metallic ions are only partially soluble or insoluble in aqueous solution [13].

These dyes have attracted much attention as the largest group of organic analytical reagents used in spectrophotometric analysis owing to the high sensitivity and selectivity [14]. In addition, they are interesting complexing agents and have been used as reagents for 
spectrophotometric and extraction-photometric determinations of transition metals such as $\mathrm{Sc}(\mathrm{III}), \mathrm{V}(\mathrm{V}), \mathrm{Cr}(\mathrm{III})$, $\mathrm{Cr}(\mathrm{VI}), \mathrm{Mn}(\mathrm{II}), \mathrm{Fe}(\mathrm{II}), \mathrm{Co}(\mathrm{II}), \mathrm{Ni}(\mathrm{II}), \mathrm{Cu}(\mathrm{II}), \mathrm{Zn}(\mathrm{II})$, $\mathrm{Mo}(\mathrm{VI}), \mathrm{Pd}(\mathrm{II}), \mathrm{Ag}(\mathrm{I}), \mathrm{Cd}(\mathrm{II}), \mathrm{Hg}(\mathrm{II}), \mathrm{Pb}(\mathrm{II})$ [15-30] and even some f-elements-Tm(III), Th(IV) and U(VI) [31-33]. Besides, 2-naphthol coupled with 2-aminothiazole derivatives gives more sensitive reagents than phenol [34].

Previously, we have discussed the synthetic possibilities of 5-benzyl-2-aminothiazoles during the synthesis of 2-[(5benzyl-1,3-thiazol-2-yl)imino]-1,3-thiazolidin-4-ones as potential biologically active compounds [35]. In order to continue the search for a new selective and sensitive chromogenic thiazolylazo dye and to study the influence of the substituent positions of a benzyl group attached to the thiazole ring on the characteristics of the reagent, we introduced a $_{6} \mathrm{H}_{5}-\mathrm{CH}_{2}-$ group into the 5-position of the thiazole ring of the well-known analytical reagent 1-(2-thiazolylazo)-2naphthol (TAN), and synthesized a new compound 1-[(5benzyl-1,3-thiazol-2-yl)diazenyl]naphthalene-2-ol $\mathbf{5}$.

In this work, we describe novel advantages of 2-amino5-benzyl-1,3-thiazole diazotization and the application of obtained diazonium salt in diazocoupling. Herein, the synthesis and properties of $\mathbf{5}$ were studied in details. It was assumed that the presence of a benzyl group in $\mathbf{5}$ can enhance the solubility of the azo dye in organic solvents (e.g., toluene) and intensify interactions with transition metal ions. Due to the application of thiazolylazo dyes in optical data storage devices, it was necessary to investigate the thermal decomposition and dissociation of the organic compound. Additionally, the possibility of determination of some transition metals using $\mathbf{5}$ was evaluated.

\section{Experimental}

\section{Synthesis}

\section{3-Phenyl-2-chloropropanal (2, $\left.\mathrm{C}_{9} \mathrm{H}_{8} \mathrm{OCl}\right)$}

At the first step, the acrolein was chloroarylated by diazonium salt in the presence of copper(II) chloride under Meerwein arylation conditions. A three-necked flask equipped with a stirrer, a dropping funnel and a gas-outlet tube (attached to a bubble counter) was charged with $0.2 \mathrm{~mol}\left(13.5 \mathrm{~cm}^{3}\right)$ of acrolein, $10 \mathrm{~g}$ of $\mathrm{CuCl}_{2} \cdot 2 \mathrm{H}_{2} \mathrm{O}$ and $50 \mathrm{~cm}^{3}$ of acetone. A cold aqueous solution of arenediazonium chloride 1 (prepared by diazotization of $0.2 \mathrm{~mol}$ of aniline) was added dropwise under vigorous stirring. The temperature was maintained within $10-30{ }^{\circ} \mathrm{C}$. When the reaction was complete, the organic layer was separated, and the aqueous layer was extracted with chloroform. The extract was combined with the organic phase, dried over $\mathrm{MgSO}_{4}$ and evaporated, and the residue was distilled under reduced pressure (bp $100{ }^{\circ} \mathrm{C} / 2 \mathrm{~mm} \mathrm{Hg}$, yield $35 \%$ ). 3-Phenyl-2-chloropropanal 2 reacted with thiourea in ethanol at refluxing and formed 2-amino-5-benzyl-1,3-thiazole 3 with a yield of $80 \%$ [36].

\section{2-Amino-5-benzylthiazole $\left(3, \mathrm{C}_{10} \mathrm{H}_{10} \mathrm{~N}_{2} \mathrm{~S}\right)$}

A mixture of thiourea $(8 \mathrm{~g})$ and aldehyde $2(0.1 \mathrm{~mol})$ in $50 \mathrm{~cm}^{3}$ of ethanol was heated for $2 \mathrm{~h}$ under reflux. The mixture was cooled, diluted with $300 \mathrm{~cm}^{3}$ of water and made alkaline by adding aqueous ammonia. The precipitate was filtered off and recrystallized from $\mathrm{CCl}_{4}\left(\mathrm{mp} 113{ }^{\circ} \mathrm{C}\right.$, yield $80 \%$ ).

\section{1-[(5-Benzyl-1,3-thiazol-2-yl)diazenyl]naphthalen-2-ol} $\left(5, \mathrm{C}_{20} \mathrm{H}_{15} \mathrm{~N}_{3} \mathrm{OS}\right)$

Since 2-amino-5-benzyl-1,3-thiazole $\mathbf{3}$ is a mild base, its efficient diazotization could be achieved only by using nitrososulfuric acid obtained from $\mathrm{NaNO}_{2}$ and concentrated $\mathrm{H}_{2} \mathrm{SO}_{4}$. 2-Amino-5-benzyl-1,3-thiazole 3 (1.9 g, $10 \mathrm{mmol})$ was dissolved in concentrated $\mathrm{H}_{2} \mathrm{SO}_{4}\left(5.2 \mathrm{~cm}^{3}\right)$ at $-5{ }^{\circ} \mathrm{C}$. The solution was diluted with $4 \mathrm{~cm}^{3}$ of water. The suspension was warmed, and a clear solution was formed. The mixture was cooled to $-10{ }^{\circ} \mathrm{C}$, after that the solution of sodium nitrite $(0.83 \mathrm{~g}, 12 \mathrm{mmol})$ in $2 \mathrm{~mL}$ of water was added dropwise while keeping the temperature below $-5{ }^{\circ} \mathrm{C}$. After $10 \mathrm{~min}$, the resinous sediment was filtered and the clear solution was added slowly with intensive stirring to the mixture of naphthalen-2-ol $(1.44 \mathrm{~g}$, $10 \mathrm{mmol}), \mathrm{NaOH}(0.4 \mathrm{~g}, 10 \mathrm{mmol}), \mathrm{Na}_{2} \mathrm{CO}_{3}(20 \mathrm{~g})$ and $20 \mathrm{~cm}^{3}$ of water. The temperature was kept below $5^{\circ} \mathrm{C}$. After diazonium salt was added, the mixture was left for $2 \mathrm{~h}$ at the room temperature and diluted with water $\left(100 \mathrm{~cm}^{3}\right)$. The precipitate was filtered off and recrystallized from ethanol-DMF.

5-Benzyl-1,3-thiazole-2-diazonium salt $\mathbf{4}$ is unstable, but it reacts in diazocoupling reaction efficiently. Diazocoupling of 5-benzyl-1,3-thiazole-2-diazonium with naphthalen-2-ol was carried out in alkaline conditions forming 1-[(5-benzyl-1,3-thiazol-2-yl)diazenyl]naphthalen-2-ol with the yield of $70 \%$.

\section{Methods and techniques}

Reagent grade chemicals were used without further purification unless otherwise noted.

The elemental analysis (C, H, N and S) was conducted using the element analyzer Vario EL III, manufactured by Elementar. Spectra were recorded as follows: UV/Vis spectra on a Jasco V-670 spectrophotometer, IR spectra in $\mathrm{KBr}$ pellets on a Bruker Alpha-P IR spectrometer in the range of $4000-400 \mathrm{~cm}^{-1},{ }^{1} \mathrm{H},{ }^{13} \mathrm{C}, \mathrm{COSY}$ and HSQC NMR 
spectra on a Bruker Avance $500 \mathrm{MHz}$ NMR spectrometer. LDI-ToF mass spectrometry experiments were performed using Bruker Autoflex Speed time-of-flight mass spectrometer equipped with a SmartBeam II laser $(355 \mathrm{~nm}$; laser impulse energy was approx. 100-150 $\mu \mathrm{J}$, laser repetition rate- $1000 \mathrm{~Hz}$ ).

The melting point was established using a Mettler Toledo differential scanning calorimeter DSC822e equipped with Haake EK90/MT intercooler. The DSC experiments have been carried out in nitrogen (gas flow $50 \mathrm{~mL} \min ^{-1}$ ) for $5.81 \mathrm{mg}$ of substance 5 in a $150 \mathrm{~mL}$ open alumina pan from 0 to $167{ }^{\circ} \mathrm{C}$, back from 167 to $0{ }^{\circ} \mathrm{C}$ and then again from 0 to $180{ }^{\circ} \mathrm{C}$ with a heating rate of $10{ }^{\circ} \mathrm{C} \min ^{-1}$.

Thermogravimetric analysis was performed using a Mettler Toledo TGA/DSC1. The TG experiments have been carried out in air and nitrogen (gas flow $50 \mathrm{~mL} \mathrm{~min}{ }^{-1}$ ) from 25 to $700{ }^{\circ} \mathrm{C}$ with a heating rate of $10{ }^{\circ} \mathrm{C} \mathrm{min}-1$, using the $150-\mathrm{mL}$ open alumina pan $(m(\mathbf{5})=6.21 \mathrm{mg})$.

TG-FTIR analyses were performed in air and nitrogen with the use of Mettler Toledo TGA/DSC1 instrument, which was online coupled with FTIR apparatus Nicolet iZ10 (Thermo Scientific) by a transfer line heated at $220{ }^{\circ} \mathrm{C}$. The FTIR spectra of the evolved gases were acquired in the range of $400-4000 \mathrm{~cm}^{-1}$ with the resolution of $4 \mathrm{~cm}^{-1}$.

\section{Results and discussion}

A new thiazolylazo reagent 1-[(5-benzyl-1,3-thiazol-2yl)diazenyl]naphthalene-2-ol has been synthesized via arylation of acrolein and further diazotization and diazocoupling with 2-naphthol. Our syntheses of the requisite 1-[(5-benzyl-1,3-thiazol-2-yl)diazenyl]naphthalen-2-ol $\mathbf{5}$ are illustrated in Figs. 1 and 2.

\section{Structural characterization}

According to the literature data, ortho-azonaphthol compounds are usually obtained in one of two tautomeric forms (azo $\mathbf{5 a}$ or hydrazone $\mathbf{5} \mathbf{b}$ form) depending on the position of the hydrogen atom of the hydroxyl group [37] (Fig. 3).

Elemental analysis values for 1-[(5-benzyl-1,3-thiazol2-yl)diazenyl]naphthalen-2-ol $\mathrm{C}_{20} \mathrm{H}_{15} \mathrm{~N}_{3} \mathrm{OS}$ (red crystals, yield $70 \%$ ); calcd: C, 69.54; H, 4.38; N, 12.17; S, 9.28; found: C, 69.31; H, 4.13; N, 11.83; S, 9.53.

\section{UV/Vis spectra}

The UV/Vis spectra of the investigated compound $\mathbf{5}$ were taken in ethanol-water mixture $(1: 1 \mathrm{v} / \mathrm{v})$ at different acidity values (Fig. 4) and characterized by the bathochromic shift of the absorption maximum from $\lambda=446 \mathrm{~nm}$ in the acidic solution of $\mathbf{5}$ to $496 \mathrm{~nm}$ in the initial solution and to 550 in the alkaline medium.

Furthermore, the interaction of the discussed compound with transition metal ions causes even more considerable bathochromic shifts. For example, the red-colored initial solution of 5 turns blue or green after the addition of mercury(II) $\left(\lambda_{\max }=630\right)$ or palladium(II) ions $\left(\lambda_{\max }=684\right)$, respectively.

\section{IR spectrum}

All peaks in the IR spectrum of $\mathbf{5}$ that could be assigned to specific types of vibrations are listed in Table 1.

An IR spectral study of $\mathbf{5}$ in a solid state has suggested that two tautomers coexist due to the presence of both hydroxyl (a broad band in the range of 3500-3200 $\mathrm{cm}^{-1}$ of $v(\mathrm{O}-\mathrm{H})$ ) and carbonyl (a sharp band at $\sim 1670 \mathrm{~cm}^{-1}$ ) groups. On the other hand, there is a band at $1618 \mathrm{~cm}^{-1}$, but it is not as strong as we might expect for a hydrazone tautomer $\left(\mathrm{C}=\mathrm{N}\right.$ stretching vibrations at $1670-1600 \mathrm{~cm}^{-1}$ [38]). On the contrary, we indicate a signal at $1596 \mathrm{~cm}^{-1}$, which may originate from vibrations of the $\mathrm{N}=\mathrm{N}$ group [39]. However, the absorption arising from the $\mathrm{N}=\mathrm{N}$ stretching vibration of aromatic azo compounds is weak and occurs in the same region as the absorption arising from the aromatic ring vibrations. Due to this, it is also hard to distinguish the band corresponding to $v(\mathrm{~N}=\mathrm{N})$ at $1360-1385 \mathrm{~cm}^{-1}$ [40].

Although the rest of the IR spectrum of $\mathbf{5}$ is overloaded with bands and it is hard to be interpreted, it was analyzed in terms of comparison with the IR spectra of such compounds as naphthalene, 2-naphthol, thiophene, 1,3-thiazole and 1-(2-thiazolylazo)-2-naphthol (TAN). It is obvious that bands at 746 and $1469 \mathrm{~cm}^{-1}$ are due to the presence of 2-naphthol group in the structure of the azo dye $\mathbf{5}$ and bands at 1144 and $1245 \mathrm{~cm}^{-1}$ come from skeletal vibrations of the 1,3-thiazole heterocycle. In general, the rest of
Fig. 1 Synthesis of 2-amino-5benzyl-1,3-thiazole 3

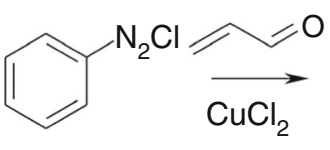

1

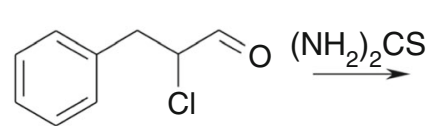

2

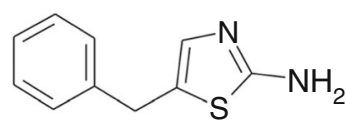

3 
Fig. 2 Synthesis of 1-[(5benzyl-1,3-thiazol-2-

yl)diazenyl]naphthalen-2-ol 5<smiles>N#[N+]c1ncc(Cc2ccccc2)s1</smiles>

Fig. 3 Tautomeric forms of 1-[(5-benzyl-1,3-thiazol-2yl)diazenyl]naphthalen-2-ol

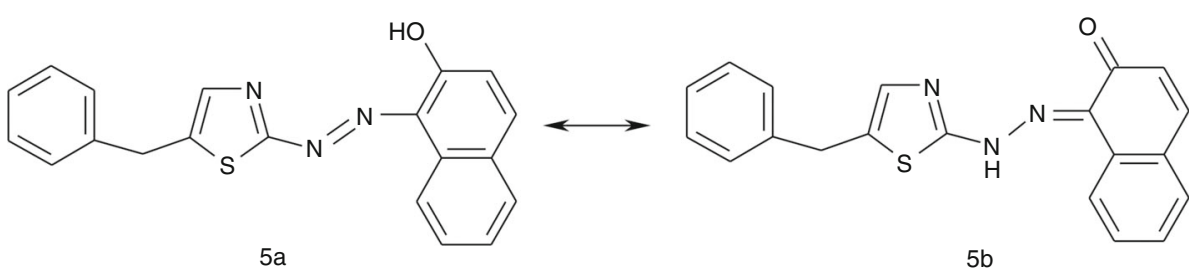

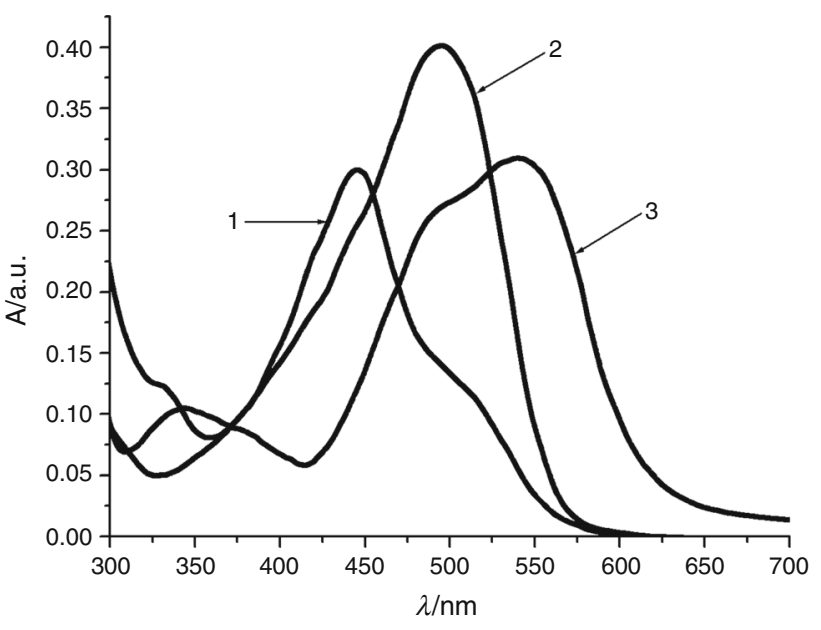

Fig. 4 UV/Vis spectra of the azo dye 5 in ethanol-water mixture (1:1 $\mathrm{v} / \mathrm{v}$ ) at different acidity values: $\mathrm{pH}=-0.20(1), 5.99(2), 13.02$ (3); $C($ BnTAN $)=2.00 \times 10^{-5} \mathrm{~mol} \mathrm{dm}{ }^{-3} ; \quad T=25^{\circ} \mathrm{C} ; \quad l=1.0 \mathrm{~cm} ;$ blank: $\mathrm{C}_{2} \mathrm{H}_{5} \mathrm{OH}-\mathrm{H}_{2} \mathrm{O}(1: 1 \mathrm{v} / \mathrm{v})$

the IR spectrum of $\mathbf{5}$ is very similar to the spectra of other thiazolylazonaphthol dyes (e.g., TAN) [41].

\section{NMR spectra}

The structure of the synthesized thiazolylazonaphthol dye (Fig. 5) was identified by one-dimensional $\left({ }^{1} \mathrm{H},{ }^{13} \mathrm{C}\right) \mathrm{NMR}$ experiments, with its spectral signals being assigned by a comparison with the data already described in the literature for thiazolylazonaphthol dyes [41]. All signals in the spectra were assigned to each atom of hydrogen and carbon and confirmed by two-dimensional (COSY, HSQC) NMR
Table 1 Assigned IR bands of the compound 5

\begin{tabular}{lll}
\hline Frequency/cm & $\begin{array}{l}\text { Type of vibration } \\
\text { and bond }\end{array}$ & Functional group \\
\hline $3063 \mathrm{~s}^{\mathrm{a}}$ & $v^{\mathrm{b}}(\mathrm{O}-\mathrm{H})$ & naphthalene-2-ol \\
$3000 \mathrm{w}$ & $v(\mathrm{C}-\mathrm{H})$ & benzyl \\
$1667 \mathrm{~s}$ & $v(\mathrm{C}=\mathrm{O})$ & naphthalene-2-one \\
$1618 \mathrm{~m}$ & $v(\mathrm{C}=\mathrm{N})$ & 1,3 -thiazole - azo \\
& $v(\mathrm{~N}=\mathrm{N})$ & group \\
$1596 \mathrm{~m}$ & $v(\mathrm{C}=\mathrm{N})$ & azo group \\
$1508 \mathrm{~s}$ & $\delta(\mathrm{O}-\mathrm{H})$ & 1,3 -thiazole \\
$1426 \mathrm{~m}$ & $v(\mathrm{C}-\mathrm{O})$ & naphthalene-2-ol \\
$1211 \mathrm{~m}$ & $v(\mathrm{C}-\mathrm{H})$ & naphthalene-2-ol \\
$1026 \mathrm{~m}$ & $v(\mathrm{~S}-\mathrm{C})$ & $1,3-$ thiazole \\
$982 \mathrm{~s}$ & $\gamma(\mathrm{C}-\mathrm{H})$ & $1,3-$ thiazole \\
$960-620$ & $v(\mathrm{C}-\mathrm{H})$ & naphthalene-2-ol, \\
& & benzyl \\
$746 \mathrm{~s}$ & & naphthalene-2-ol \\
\hline
\end{tabular}

a Intensity: $s$ strong, $m$ medium, $w$ weak

b Symbols $v, \delta$ and $\gamma$ mean stretching, in-plane and out-of-plane deformation, respectively

techniques (Fig. 6). The $\delta$ values of all protons and carbons of the azo compound are listed in Table 2.

The only difference between the compound 5 and TAN is the presence of the benzyl substituent in the 13 position. In this case, the characteristic signal for the $\mathrm{C} 13-\mathrm{H}$ proton of TAN at $\sim 7.2 \mathrm{ppm}$ was not observed on the NMR spectra of 5 . Besides, the signal of $\mathrm{C} 13$ on the ${ }^{13} \mathrm{C}$ NMR spectrum was shifted from $117 \mathrm{ppm}$ for TAN to $123 \mathrm{ppm}$ for 5. This confirms that we have obtained a compound substituted in a proper position. 
It is also worth mentioning that the signals from the C3-H and C4-H protons differ significantly, suggesting that the signals of such two protons in aromatic systems should be closer. It is assumed that this phenomenon is connected with the presence of the hydrazone tautomeric form in the $\mathrm{CDCl}_{3}$ solution. Probably, the predominant form of $\mathbf{5}$ in the analyzed solution is that with $\mathrm{H}$ bound to $\mathrm{N}$ atom of thiazole.

\section{Mass spectrum}

The structure of the new product $\mathbf{5}$ was also analyzed with mass spectrometry method. Peaks of all expected adducts of 5 were registered in the mass spectrum recorded according to the surface-assisted laser desorption/ionization (SALDI) technique [42]. The molecule of the azo dye on gold nanoparticle-covered targets (AuNPET) has created such ions as $[\mathrm{M}+\mathrm{H}]^{+}(\mathrm{m} / \mathrm{z}=346.12),[\mathrm{M}+\mathrm{Na}]^{+}$

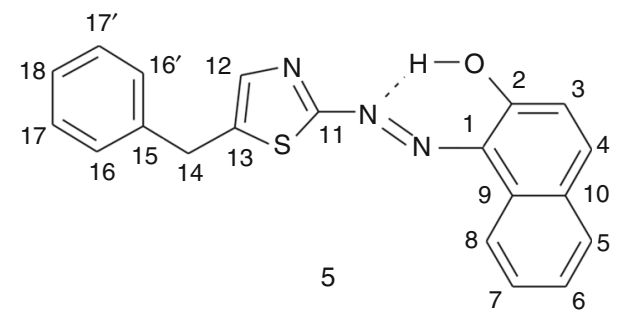

Fig. 5 Numbering of the azo dye 5 to NMR data $(m / z=368.09)$ and $\left[\mathrm{M}-\mathrm{H}_{2} \mathrm{O}+\mathrm{H}\right]^{+}(\mathrm{m} / \mathrm{z}=328.09)$ with signals of high intensity and $[\mathrm{M}+\mathrm{K}]^{+}$ion $(\mathrm{m} / \mathrm{z}=384.06)$ of a weaker signal.

\section{DSC/TG studies}

The thermal properties of the azo dye were investigated by differential scanning calorimetry (DSC, temperature range $0-180{ }^{\circ} \mathrm{C}$ ), thermogravimetric (TG), differential thermogravimetric (DTG) and differential thermal (DTA) analyses.

Figure 7 presents the recorded DSC curve for 5 in nitrogen atmosphere. It can be seen that the melting of the substance starts at $T_{\text {fus }}=159.7^{\circ} \mathrm{C} \quad\left(\Delta H_{\text {fus }}=28.0\right.$ $\left.\mathrm{kJ} \mathrm{mol}^{-1}\right)$. On cooling, the liquid crystallizes at $123.0^{\circ} \mathrm{C}$. Then the substance was heated again, and it was found that the melting point occurs at lower temperature $\left(151.1^{\circ} \mathrm{C}\right)$ which can be explained by a process of degradation of the azo dye right after the melting. It is also worth mentioning that N,N-dimethylformamide (DMF) which was used during the synthesis of the azo compound has a boiling point of $153.3^{\circ} \mathrm{C}$ [43].

This phenomenon was checked in details using TG/ DTG/DTA curves (Fig. 8). The FTIR spectra of the evolved gases were recorded at the temperatures of every peak on the DTG curve (Fig. 9). The correlations between different decomposition steps of the azo dye with corresponding mass losses are discussed in terms of the molecular formula of $\mathbf{5}$. The thermal decomposition
Fig. 6 2D NMR HSQC spectrum of the azo dye $\mathbf{5}$

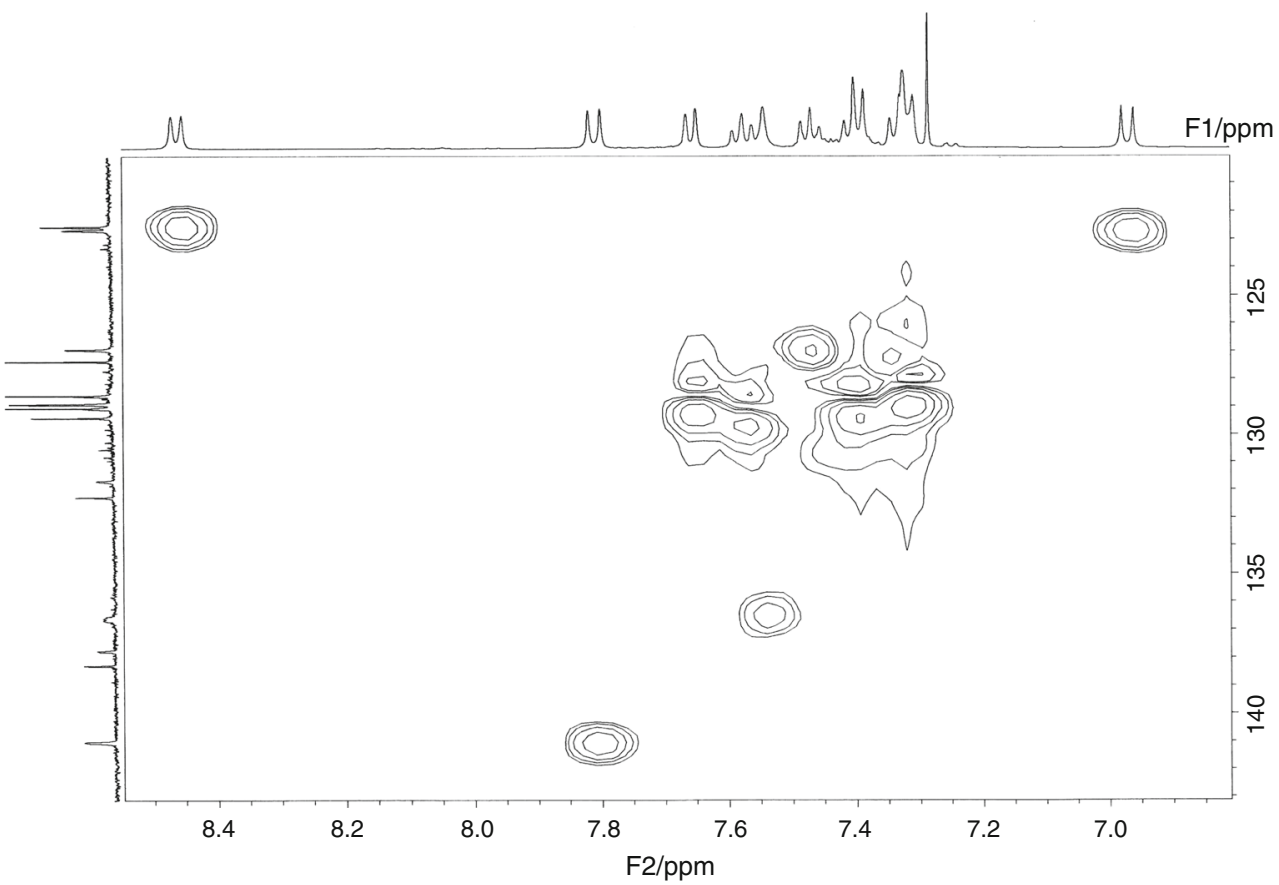


Table $2{ }^{1} \mathrm{H},{ }^{13} \mathrm{C}$, COSY and HSQC NMR data of the compound 5

\begin{tabular}{llllll}
\hline Position & Carbon $\delta / \mathrm{ppm}$ & Proton $\delta / \mathrm{ppm}$ & Position & Carbon $\delta / \mathrm{ppm}$ & Proton $\delta / \mathrm{ppm}$ \\
\hline $\mathrm{C}(1)$ & 130.85 & - & $\mathrm{C}(11)$ & 166.60 & - \\
$\mathrm{C}(2)$ & 172.36 & - & $\mathrm{C}(12)$ & 136.91 & 7.52 \\
$\mathrm{C}(3)$ & 122.97 & 6.94 & $\mathrm{C}(13)$ & 123.62 & - \\
$\mathrm{C}(4)$ & 141.35 & 7.78 & $\mathrm{C}(14)$ & 34.28 & 4.17 \\
$\mathrm{C}(5)$ & 129.71 & 7.45 & $\mathrm{C}(15)$ & 138.60 & - \\
$\mathrm{C}(6)$ & 129.35 & 7.63 & $\mathrm{C}(16)$ & 129.22 & $7.40-7.35$ \\
$\mathrm{C}(7)$ & 127.25 & 7.56 & $\mathrm{C}(17)$ & 128.90 & $7.33-7.28$ \\
$\mathrm{C}(8)$ & 122.86 & 8.43 & $\mathrm{C}(18)$ & 127.67 & $7.33-7.28$ \\
$\mathrm{C}(9)$ & 132.58 & - & $\mathrm{O}$ & - & 14.85 \\
$\mathrm{C}(10)$ & 132.00 & - & & & \\
\hline
\end{tabular}

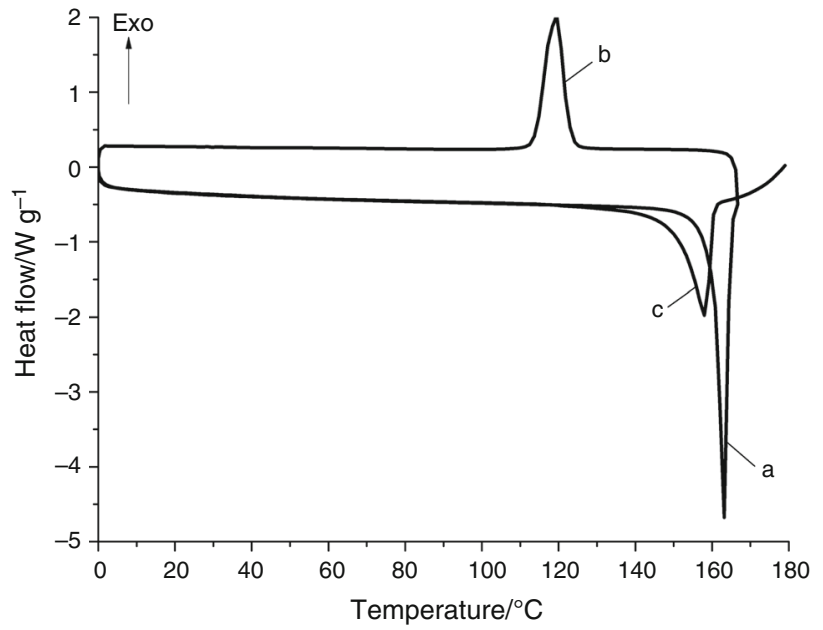

Fig. 7 DSC curves for the melting $(a, c)$ and crystallization (b) processes of $\mathbf{5}$ behavior of the substance is similar to other azo dyes previously described in the literature [44-48].

The TG and DTG curves show that the substance undergoes decomposition in five stages. In fact, the first DTG peak at the temperature $160{ }^{\circ} \mathrm{C}$ is accompanied with a sharp endothermic peak on a DTA curve which corresponds to the melting point of 5. A small mass loss $(0.45 \%)$ at the first stage is probably connected with the evaporation of some impurities of the solvent previously used for recrystallization. The first FTIR spectrum confirms that it was DMF (absorption bands at $\sim 1700$ and $2950 \mathrm{~cm}^{-1}$ ).

The sharp exothermic peak in the DTA curve corresponds to the second decomposition stage with a mass loss of $5.20 \%$ in the temperature range of $182-207^{\circ} \mathrm{C}$. At these temperatures, the azo bonds in the dye breakdown. According to the literature, molecular nitrogen and two
Fig. 8 TG (a), DTG (b) and DTA $(c)$ curves of 5

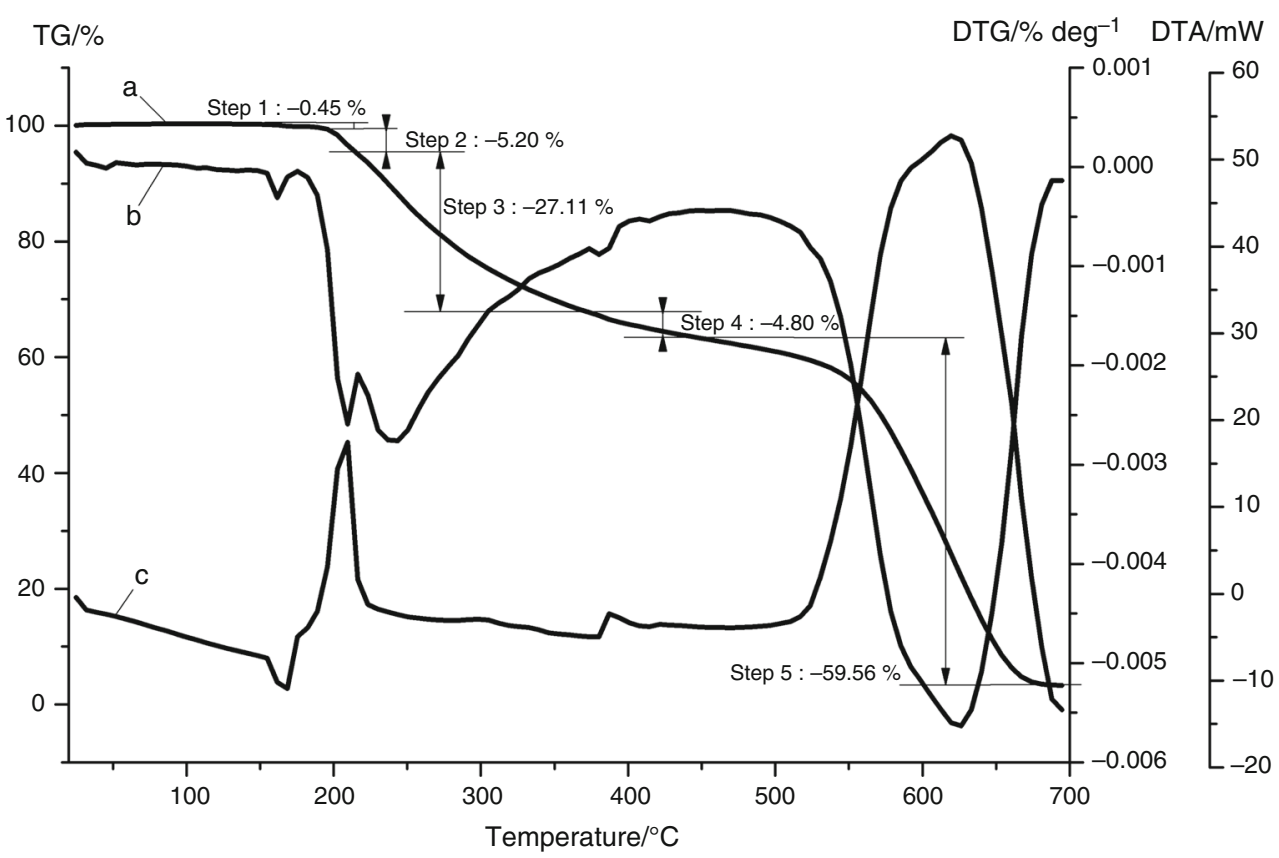


radicals of the residual organic parts are formed [45]. Unfortunately, $\mathrm{N}_{2}$ cannot be identified in the FTIR spectrum because of the absence of a dipole. In the spectrum, there appears a clear signal from ammonia molecules (strong band at $\sim 950 \mathrm{~cm}^{-1}$, medium at $\sim 1550 \mathrm{~cm}^{-1}$ and weak at $\left.3300 \mathrm{~cm}^{-1}\right)$. Calculated mass loss $(4.92 \%)$ agrees well with experimental value. This could mean that the predominant tautomeric form of the azo dye is a hydrazone form where a hydrogen atom is bound to the nitrogen of the azo group instead of oxygen.

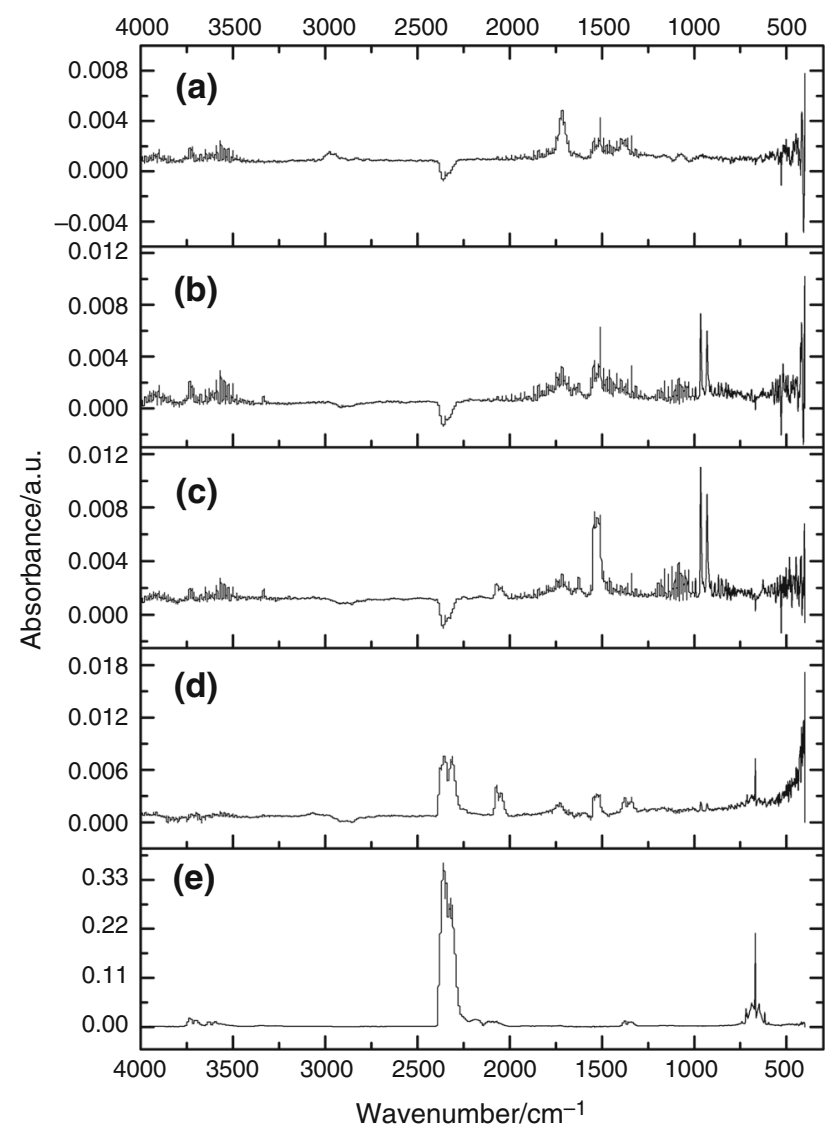

Fig. 9 FTIR spectra of the evolved gases from $\mathbf{5}$ at different temperatures $\left(a 164.6{ }^{\circ} \mathrm{C}, b 208.8^{\circ} \mathrm{C}, c 250.1^{\circ} \mathrm{C}, d 388.8^{\circ} \mathrm{C}\right.$ and e $\left.623.7^{\circ} \mathrm{C}\right)$
The third peak in the DTG curve is connected with further degradation of the compound (mass loss $27.11 \%$ ). Signals of ammonia become stronger because of the destruction of the thiazol heterocyclic ring. Then, a small fourth DTG peak at $383{ }^{\circ} \mathrm{C}$ is accompanied with the DTA exothermic maximum. According to the FTIR spectrum, molecules of $\mathrm{SO}_{2}$ evolve at this stage (bands at $\sim 1350$ and $400 \mathrm{~cm}^{-1}$ ). The mass loss of $4.80 \%$ corresponds to that calculated if half of the sulfur content $9.27 \%$ were lost per molecule of 5. Signals of CO (2000-2100 $\left.\mathrm{cm}^{-1}\right)$ and $\mathrm{CO}_{2}\left(2300-2400 ; 650 \mathrm{~cm}^{-1}\right)$ can also be found in this spectrum.

Finally, at the fifth decomposition stage a broad exothermic peak at $626{ }^{\circ} \mathrm{C}$ indicates the pyrolysis of the rest of the organic sample $[47,48]$. Above $520{ }^{\circ} \mathrm{C}$ only the signals of $\mathrm{CO}_{2}$ can be observed in the FTIR spectrum (mass loss $59.56 \%$ ). At $700{ }^{\circ} \mathrm{C}$ the investigated compound has almost completely burnt down with a residue of $2.88 \%$.

In order to determine the thermal stability trend, three main criteria for the thermal stability of the dye in the air were calculated, i.e., temperature of the onset of decomposition $T_{0}=171{ }^{\circ} \mathrm{C}$, temperature for $10 \%$ mass loss $T_{10}=238{ }^{\circ} \mathrm{C}$ and temperature for $50 \%$ mass loss $T_{50}=572{ }^{\circ} \mathrm{C}$.

Due to the presence of split and shoulder peaks on DTG curve which indicate complex structural changes in the compound, the detailed mechanism of degradation of the azo dye could not be derived from these thermal data and mass losses.

As to the TG/DTG/DTA curves in nitrogen atmosphere, they have the similar shape as those in air atmosphere, though the last two stages do not take place in the inert medium due to the absence of oxygen for combustion. That is why, the residue at $700{ }^{\circ} \mathrm{C}$ is bigger- $-33.6 \%$.

\section{Analytical applications}

As it has been already mentioned above, azo dyes like $\mathbf{5}$ have several beneficial applications in analytical chemistry. Depending on the medium acidity, the red-colored compound 5 can exist in a yellow protonated form and violet deprotonated form (Fig. 10). So, first of all, this

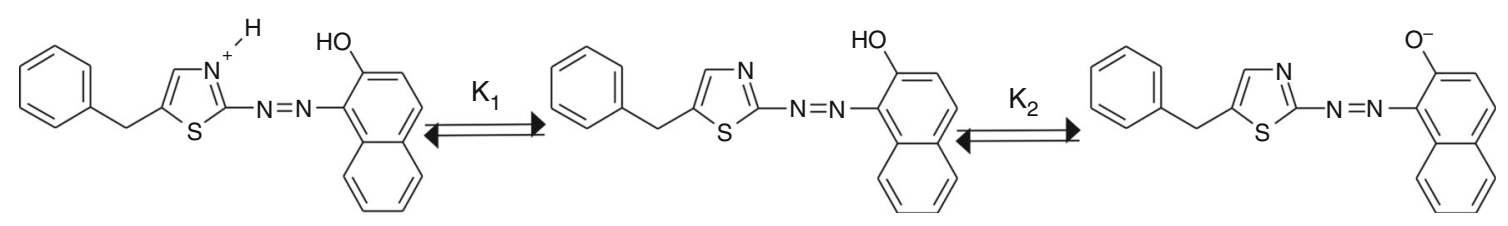

Fig. 10 Protonated, unprotonated and deprotonated form of the azo dye $\mathbf{5}$ 
thiazolylazo dye may be applied as a useful indicator in acid-base titrations.

For this purpose, the $p K_{\mathrm{a}}$ values of the protonated and undissociated forms of $\mathbf{5}$ have been determined at $25{ }^{\circ} \mathrm{C}$ in $50 \% / \mathrm{v}$ ethanol-water mixture by means of the spectroscopic method (Table 3). Spectrophotometric titration was carried out because it requires small amounts of the analyzed substance and it is commonly used when a compound does not have enough solubility for the potentiometric determination [49]. According to the experimental data, the protonation of $\mathbf{5}$ occurs in a solution of a very strong acidity $(\mathrm{pH} \sim 0.4)$. The $p K_{\mathrm{a} 2}$ value of $\mathbf{5}$ is very similar to the respective value of the classic indicator phenolphthalein $\left(p K_{\mathrm{a}}=9.7\right.$ [50]), so the azo dye could be easily used in acid-base titrations.

Table $3 p K_{\mathrm{a} 1}$ and $p K_{\mathrm{a} 2}$ values of $\mathbf{5}$ calculated at different wavelengths

\begin{tabular}{|c|c|c|c|c|c|c|c|}
\hline \multirow[t]{2}{*}{$\mathrm{pH}$} & \multicolumn{3}{|l|}{$\lambda / \mathrm{nm}$} & \multirow[t]{2}{*}{ pH } & \multicolumn{3}{|l|}{$\lambda / \mathrm{nm}$} \\
\hline & 446 & 496 & 550 & & 446 & 496 & 550 \\
\hline 0.03 & 0.97 & 0.62 & 0.78 & 8.96 & 9.35 & 9.23 & 9.53 \\
\hline 0.23 & 0.42 & 0.26 & 0.42 & 9.41 & 9.47 & 9.34 & 9.67 \\
\hline 0.48 & 0.32 & 0.11 & 0.35 & 9.85 & 9.62 & 9.48 & 9.76 \\
\hline \multirow[t]{2}{*}{0.76} & 0.28 & 0.01 & 0.41 & 10.26 & 9.79 & 9.65 & 9.89 \\
\hline & & & & 10.64 & 9.70 & 9.44 & 9.99 \\
\hline Mean & \multicolumn{3}{|c|}{$p K_{\mathrm{a} 1}=0.41 \pm 0.17$} & Mean & \multicolumn{3}{|c|}{$p K_{\mathrm{a} 2}=9.59 \pm 0.14$} \\
\hline
\end{tabular}

Another application of $\mathbf{5}$ is the determination of trace amounts of transition metal ions. Even small concentrations of such toxic metallic ions as $\mathrm{Cd}^{2+}$ or $\mathrm{Hg}^{2+}$ in environmental objects could cause very dangerous illnesses or death. Fortunately, they can be determined with the azo dye 5 by means of the spectrophotometric or extractionphotometric methods.

Thiazolylazonaphthol compound $\mathbf{5}$ creates in aqueous solution stable chelate complexes with ions such as $\mathrm{Zn}^{2+}$, $\mathrm{Cd}^{2+}, \mathrm{Hg}^{2+}, \mathrm{Cu}^{2+}, \mathrm{Co}^{2+}, \mathrm{Ni}^{2+}$ and $\mathrm{Pd}^{2+}$ causing the bathochromic shift on the UV/Vis spectrum of $\mathbf{5}$. Most of these complexes are poorly soluble in water because the molecule of the azo compound does not have a single strong hydrophilic group. In this case, some organic solvents should be used as the extractant. Toluene proved to be the best solvent for the extraction of chelates. Probably, it is due to the resemblance between the structure of toluene and a benzyl group that was attached to the molecule of the dye. So, it can be assumed that the substance 5 is much better soluble in toluene than other azo reagents according to a popular aphorism "Similia similibus solventur" ("like dissolves like") [51].

Basing on this, sensitive methods for the transition metals determination were developed (Table 4) and successfully tested on model solutions and real environmental samples (waters, soils, etc.). Some specific reaction conditions were determined to minimize the influence of diverse ions and selectively determine necessary ions.

Table 4 Characteristics of spectrophotometric procedures involving the azo reagent 5

\begin{tabular}{|c|c|c|c|c|c|c|c|}
\hline Ion & $\mathrm{pH}$ & Medium & $\begin{array}{l}\text { Ion/reagent ratio and } \\
\text { conditions }\end{array}$ & $\begin{array}{l}\text { Wavelength } \\
\lambda_{\max } / \mathrm{nm}\end{array}$ & $\begin{array}{l}\text { Molar absorptivity } \\
\varepsilon \times 10^{-4} / \mathrm{mol}^{-1} \mathrm{dm}^{3} \mathrm{~cm}^{-1}\end{array}$ & $\begin{array}{l}\text { Detection } \\
\text { limit/ppb }\end{array}$ & Sample \\
\hline $\mathrm{Zn}^{2+}$ & 8 & Toluene & $1: 2$ & 590 & 0.97 & 160 & Water \\
\hline $\mathrm{Zn}^{2+}$ & 11 & $\mathrm{CCl}_{4}$ & $1: 2$ & 600 & 2.1 & 79 & Alloys, soils \\
\hline $\mathrm{Cd}^{2+}$ & 13 & Toluene & $1: 2$ & 595 & 1.9 & 100 & Water \\
\hline $\mathrm{Cd}^{2+}$ & 13 & $\mathrm{CCl}_{4}$ & $1: 2$ & 595 & 1.9 & 168 & Alloys, soils \\
\hline $\mathrm{Hg}^{2+}$ & 8 & $\begin{array}{l}\text { Water saturated } \\
\text { with toluene }\end{array}$ & $\begin{array}{l}1: 3 ; 5 \text { min after } \\
\text { preparation }\end{array}$ & 630 & 3.56 & 81.6 & Soils \\
\hline $\mathrm{Cu}^{2+}$ & 6 & $\mathrm{CCl}_{4}$ & $1: 2$ & 590 & 2.2 & 108 & Alloys, soils \\
\hline $\mathrm{Cu}^{2+}$ & 5 & Water & $\begin{array}{l}\text { 1:2; presence of Triton } \\
\quad \mathrm{X}-100\end{array}$ & 596 & 4.38 & - & Water \\
\hline $\mathrm{Co}^{2+}$ & 11 & Toluene & $1: 2$ & 565 & 1.08 & 160 & Water, glass \\
\hline $\mathrm{Ni}^{2+}$ & 10 & Toluene & $\begin{array}{l}1: 2 ; 5 \text { min heating of } \\
\text { aqueous solution }\end{array}$ & 610 & 1.56 & 57 & Water \\
\hline $\mathrm{Pd}^{2+}$ & 1 & $\mathrm{CHCl}_{3}$ & $\begin{array}{l}1: 1 ; 30 \text { min heating of } \\
\text { aqueous solution }\end{array}$ & 684 & 0.67 & 96 & $\begin{array}{l}\text { Details of } \\
\text { electronic } \\
\text { devices }\end{array}$ \\
\hline
\end{tabular}




\section{Conclusions}

In conclusion, we have synthesized and characterized a new azo reagent 1-[(5-benzyl-1,3-thiazol-2-yl)diazenyl]naphthalene-2-ol. It was prepared in the efficient synthetic procedure involving Meerwein arylation, diazotization and diazocoupling. This method can be an excellent synthetic route to new diazo colors as potential analytical reagents.

The obtained compound is thermally stable up to $171^{\circ} \mathrm{C}$. The further decomposition of the substance takes place in five consecutive stages and ends at $\sim 680{ }^{\circ} \mathrm{C}$. Thiazolylazonaphthol dye was found to be a sensitive and selective analytical reagent for the determination of such transition metal ions as $\mathrm{Cd}^{2+}, \mathrm{Hg}^{2+}, \mathrm{Pd}^{2+}$. Moreover, according to the results of the ionization constants determination, the substance $\mathbf{5}$ could be successfully used as the indicator in acid-base titrations. Furthermore, the reviewed azo dye may be active against cancer cells because of the presence of thiazol heterocycle.

Acknowledgements The authors are grateful to the Government of the Republic of Poland for their financial support of this work according to the program "Polish Erasmus for Ukraine" for graduate students. We also thank Prof Tomasz Ruman from the Department of Polymer Technology, Rzeszow University of Technology, for recording NMR spectra, and Dr Beata Mossety-Leszczak from the Department of Industrial and Materials Chemistry for carrying out DCS studies.

Open Access This article is distributed under the terms of the Creative Commons Attribution 4.0 International License (http://crea tivecommons.org/licenses/by/4.0/), which permits unrestricted use, distribution, and reproduction in any medium, provided you give appropriate credit to the original author(s) and the source, provide a link to the Creative Commons license, and indicate if changes were made.

\section{References}

1. Furukawa M. Syntheses and spectrophotometric studies of 2-(2thiazolylazo)- and 2-(2-benzothiazolylazo)-5-dimethylaminobenzoic acids as analytical reagents: determination of nickel. Anal Chim Acta. 1982;140:281-9.

2. Devia A, de Sosa GZ, Estrada M, Nemzoff G. Theoretical studies on the molecular structure of 1,3-benzenediamine,4-(2-thiazolylazo). J Mol Struct Theochem. 1989;188:141-7.

3. Lemos VA, Santos ES, Santos MS, Yamaki RT. Thiazolylazo dyes and their application in analytical methods. Microchim Acta. 2007;158:189-204.

4. Wang S, Shen S, Xu H, Gu D, Yin J, Dong X. Metallized thiazolylazo dyes as optical recording materials. Mater Sci Eng B-Solid. 2001;79:45-8.

5. Hyeyoung P, Eung-Ryul K, Dong JK, Haiwon L. Synthesis of metal-azo dyes and their optical and thermal properties as recording materials for DVD-R. Bull Chem Soc Jpn. 2002;75:2067-70.

6. Ogawa K. Two-photon absorbing molecules as potential materials for 3D optical memory. Appl Sci. 2014;4:1-18.
7. Ahlström L, Eskilsson CS, Björklund E. Determination of banned azo dyes in consumer goods. Trends Anal Chem. 2005;24:49-56.

8. Pytlakowska K, Kozik V, Dabioch M. Complex-forming organic ligands in cloud-point extraction of metal ions: a review. Talanta. 2013;100:202-28.

9. Wang H, Zhang HS, Cheng JK. Studies on 2-(2-thiazolylazo)-5diethylaminophenol as a precolumn derivatizing reagent in the separation of platinum group metals by high performance liquid chromatography. Talanta. 1999;48:1-7.

10. Lee W, Lee S-E, Lee C-H, Kim Y-S, Lee Y-I. A chelating resin containing 1-(2-thiazolylazo)-2-naphthol as the functional group; synthesis and sorption behavior for trace metal ions. Microchem J. 2001;70:195-203.

11. Baliza PX, Ferreira SLC, Teixeira LSG. Application of pyridylazo and thiazolylazo reagents in flow injection preconcentration systems for determination of metals. Talanta. 2009;79:2-9.

12. Yamaki RT, Vieira DR, Novaes CG, de Oliveira HR, Lemos VA. Application of a thiazolylazo dye as an acid-base indicator and determination of its acid ionization constants. Quim Nova. 2009;32:1943-6.

13. Bezerra MA, Arruda MAZ, Ferreira SLC. Cloud point extraction as a procedure of separation and preconcentration for metal determination using spectroanalytical techniques: a review. Appl Spectrosc Rev. 2005;40:269-99.

14. Fan X, Zhang G, Zhu C. Synthesis of 2-[2-(5-methylbenzothiazolyl) azo]-5-dimethylaminobenzoic acid and its application to the spectrophotometric determination of nickel. Analyst. 1998;123:109-12.

15. Bhalotra A, Puri BK. Column preconcentration and second derivative spectrophotometric trace determination of scandium in standard biological and synthetic samples using 1-(2-Thiazolylazo)-2-naphthol. Anal Sci. 2000;16:507-11.

16. Eshwar MC, Sharma CD. Rapid spectrophotometric determination of vanadium(V) with 1-(2'-thiazolylazo)-2-naphthol. Microchem J. 1987;35:27-9.

17. Rathaiah GV, Eshwar MC. Rapid spectrophotometric determination of chromium(III) with 1-(2-Thiazolylazo)-2-naphthol in presence of surfactant. Bull Chem Soc Jpn. 1985;58:2447-8.

18. Wang L-L, Wang J-Q, Zheng Z-X, Xiao P. Cloud point extraction combined with high-performance liquid chromatography for speciation of chromium(III) and chromium(VI) in environmental sediment samples. J Hazard Mater. 2010;177:114-8.

19. Chavan SS, Sawant VA. Synthesis, structural characterization, thermal and electrochemical studies of $\mathrm{Mn}(\mathrm{II}), \mathrm{Co}(\mathrm{II}), \mathrm{Ni}(\mathrm{II})$ and $\mathrm{Cu}(\mathrm{II})$ complexes containing thiazolylazo ligands. J Mol Struct. 2010;965:1-6.

20. Ferreira SLC, Nano RMW. Use of 1-(2-thiazolylazo) 2-naphthol in rapid determination of iron in geological matrices. Talanta. 1994;41:1937-41.

21. Niazi A, Yazdanipour A. Simultaneous spectrophotometric determination of cobalt, copper and nickel using 1-(2-thiazolylazo)-2-naphthol by chemometrics methods. Chinese Chem Lett. 2008;19:860-4.

22. Jamali MR, Madadjo A, Rahnama R. Determination of nickel using cold-induced aggregation microextraction based on ionic liquid followed by flame atomic absorption spectrometry. J Anal Chem. 2014;69:426-31.

23. Samadi A, Amjadi M. Magnetic $\mathrm{Fe}_{3} \mathrm{O}_{4} @ \mathrm{C}$ nanoparticles modified with 1-(2-thiazolylazo)-2-naphthol as a novel solid-phase extraction sorbent for preconcentration of copper (II). Microchim Acta. 2015;182:257-64.

24. Ferreira SLC, Araujo NML, Santos AB, Dantas AF. Spinola Costa AC. Spectrophotometric determination of zinc in copperbase alloys with TAN. Microchim Acta. 1995;118:123-9. 
25. Amin AS. Determination of molybdenum in human urine by spectrophotometric method using thiazolylazo compounds as chromogenic reagents. Anal Lett. 1999;32:1575-87.

26. Tupys A, Tymoshuk O. 1-(5-Benzylthiazol-2-yl)azonaphthalen2-ol-a new reagent for the determination of $\mathrm{Pd}(\mathrm{II})$. Acta Chimica Slovaca. 2015;8:59-64.

27. Kulichenko SA, Doroshchuk VA, Lelyushok SA, Sopilnyak OY, Ishchenko VB. Micellar extraction preconcentration of silver with thiazolylazo reagents into a nonionic surfactant phase at the cloud point. J Anal Chem. 2007;62:940-5.

28. Chavan SS, Yamgar BA, Bharate BG. Zn(II) and Cd(II)-azido/ thiocyanato complexes with thiazolylazo dye and triphenylphosphine: synthesis, characterization and fluorescence. J Coord Chem. 2013;66:1837-46.

29. Hosseini-Bandegharaei A, Hosseini MS, Jalalabadi Y, Sarwghadi M, Nedaie M, Taherian A, Ghaznavi A, Eftekhari A. Removal of $\mathrm{Hg}(\mathrm{II})$ from aqueous solutions using a novel impregnated resin containing 1-(2-thiazolylazo)-2-naphthol (TAN). Chem Eng J. 2011;168:1163-73.

30. Tokalioglu S, Yilmaz V, Kartal S. Solid phase extraction of $\mathrm{Cu}(\mathrm{II}), \mathrm{Ni}(\mathrm{II}), \mathrm{Pb}(\mathrm{II}), \mathrm{Cd}(\mathrm{II})$ and $\mathrm{Mn}$ (II) ions with 1-(2-thiazolylazo)-2-naphthol loaded Amberlite XAD-1180. Environ Monit Assess. 2009;152:369-77.

31. Zamani HA, Nekoei M, Mohammadhosseini M, Ganjali MR. Construction of $\mathrm{Tm}^{3+}$-PVC membrane sensor based on 1-(2thiazolylazo)-2-naphthol as sensing material. Mater Sci Eng C. 2010;30:480-3.

32. Sharma CD, Eshwar MC. Rapid spectrophotometric determination of thorium(IV) with 1-(2'-thiazolylazo)-2-naphthol. J Radioan Nucl Ch Ar. 1985;91:323-8.

33. Rathaiah GV, Krishnama Charyulu J, Eshwar MC. Spectrophotometric determination of uranium(VI) with 1-( $2^{\prime}$-Thiazolylazo)2-naphthol in the presence of triton X-100. J Radioanal Nucl Chem Ar. 1986;99:337-44.

34. Hovind HR. Thiazolylazo dyes and their applications in analytical chemistry. Analyst. 1975;100:769-96.

35. Ostapiuk YV, Obushak MD, Matiychuk VS, Naskrent M, Gzella AK. A convenient method for the synthesis of 2-[(5-benzyl-1,3thiazol-2-yl)imino]-1,3-thiazolidin-4-one derivatives. Tetrahedron Lett. 2012;53:543-5.

36. Obushak ND, Matiichuk VS, Vasylyshin RY, Ostapyuk YV. Heterocyclic syntheses on the basis of arylation products of unsaturated compounds: $\mathrm{X}$.* 3-Aryl-2-chloropropanals as reagents for the synthesis of 2-Amino-1,3-thiazole derivatives. Russ J Org Chem. 2004;40:383-9.

37. Kurahashi M. The crystal and molecular structure of 1-(2-Thiazolylazo)-2-naphthol. Bull Chem Soc Jpn. 1976;49:2927-33.

38. Simons WW. The Sadtler handbook of INFRARED spectra. Philadelphia: Sadtler Research Laboratories; 1978.
39. Płotek M, Starosta R, Nitek W, Komarnicka UK, Stochel G, Kyzioł A. Synthesis and characterization of copper(I) coordination compounds with (1-(2-pyridylazo)-2-naphthol) and (4-(2pyridylazo)resorcinol). Polyhedron. 2014;68:357-64.

40. Bag K, Misra TK, Sinha C. Studies on some reactions of cyclopalladated azobenzenes with N,O-chelators. Polyhedron. 1998;17:4109-14.

41. Yamaji T, Saito T, Hayamizu K, Yanagisawa M, Yamamoto O, Wasada N, Someno K, Kinugasa S, Tanabe K, Tamura T, Tanabe K, Hiraishi J. Spectral Database for Organic Compounds, SDBS, National Institute of Advanced Industrial Science and Technology (AIST), Japan. 2012. http://riodb01.ibase.aist.go.jp/sdbs/cgibin/cre_index.cgi?lang=eng. Accessed 23 Jan 2015.

42. Sekuła J, Nizioł J, Rode W, Ruman T. Gold nanoparticle-enhanced target (AuNPET) as universal solution for laser desorption/ionization mass spectrometry analysis and imaging of low molecular weight compounds. Anal Chim Acta. 2015;875:61-72.

43. Janowska G, Rybiński P. Thermal properties of swollen butadiene-acrylonitrile rubber vulcanizates. J Therm Anal Calorim. 2004;78:839-47.

44. Karipcin F, Dede B, Percin-Ozkorucuklu S, Kabalcilar E. Mn(II), $\mathrm{Co}(\mathrm{II})$ and $\mathrm{Ni}(\mathrm{II})$ complexes of 4-(2-thiazolylazo)resorcinol: syntheses, characterization, catalase-like activity, thermal and electrochemical behaviour. Dyes Pigments. 2010;84:14-8.

45. Li X, Wu Y, Gu D, Gan F. Spectral, thermal and optical properties of metal(II)-azo complexes for optical recording media. Dyes Pigments. 2010;86:182-9.

46. Gallo B, Arnaiz AR, Santiago C. Thermal decomposition of 3-(4,5-dimethyl-2-thiazolylazo)-2,6-diaminopyridine. Thermochim Acta. 1988;124:35-42.

47. Mahmoud WH, Omar MM, Sayed FN. Synthesis, spectral characterization, thermal, anticancer and antimicrobial studies of bidentate azo dye metal complexes. J Therm Anal Calorim. 2016;124:1071-89.

48. Moanta A, Ionescu C, Dragoi M, Tutunaru B, Rotaru P. A new azo-ester: 4-(phenyldiazenyl)phenyl benzene sulfonate-Spectral, thermal, and electrochemical behavior and its antimicrobial activity. J Therm Anal Calorim. 2016;120:1151-61.

49. Zhang L, Song L, Zhang P, Liu T, Zhou L, Yang G, Lin R, Zhang J. Solubilities of naringin and naringenin in different solvents and dissociation constants of naringenin. J Chem Eng Data. 2015;60:932-40.

50. Alonso M, Chapela SP, Cristaldo ML, Nievas I, Burgos HI, Gamondi O, Stella CA. Determination of the pKa value of phenolphthalein by means of absorbance measurements. Creat Educ. 2010;2:130-3.

51. Williamson KJ. Macroscale and microscale organic experiments. 2nd ed. Lexington: D.C. Heath and Company; 1994. 